\title{
Glycogenesis in the Cultured Fetal and Adult Rat Hepatocyte Is Differently Regulated by Medium Glucose
}

\author{
QINGJUN ZHENG, LYNNE L. LEVITSKY, JIONG FAN, NANCY CILETTI, AND KATHY MINK \\ Pediatric Endocrine Unit, Massachusetts General Hospital, Harvard Medical School, Boston, Massachusetts \\ 02114: and Section of Pediatric Endocrinology, Department of Pediatrics, Wyler Children's Hospital, Pritzker \\ School of Medicine, University of Chicago, Chicago, Illinois 60637
}

\begin{abstract}
We examined the glycogenic response to glucose in cultured fetal and adult rat hepatocytes. After a 48-h culture in Dulbecco's modified Eagle's medium, 1 $\mathrm{mM}$ glucose, insulin, and cortisol, cells were cultured for $4 \mathrm{~h}$ in serum-free medium containing glucose $(1-30 \mathrm{mM})$ and $\mathrm{U}_{-}{ }^{14} \mathrm{C}$-glucose. Incorporation of ${ }^{14} \mathrm{C}$-glucose into glycogen was greater in fetal hepatocytes compared with adult hepatocytes at all glucose concentrations $(p<0.001)$. Net glycogenic rate in fetal cells was greatest between 1 and $8.3 \mathrm{mM}$ (7.7- \pm 1.1 -fold increase) compared with a 3.8 \pm 0 .6-fold increase in adult cells. In contrast, there was a 19.4- \pm 2.7 -fold increase in glycogen accumulated between 8.3 and $30 \mathrm{mM}$ glucose in the adult and a 1.6- \pm 0.1 -fold increase in the fetus. Total glycogen synthetase activity was higher in fetal than adult hepatocytes $(p<0.001)$, but the active a form was similar in fetal and adult hepatocytes. Glycogen synthase $a / a+b$ was stimulated at $8.3 \mathrm{mM}$ or greater glucose in fetal hepatocytes, and $5.7 \mathrm{mM}$ or greater in adult hepatocytes $(p<0.05)$. Total phosphorylase did not change with medium glucose, but glycogen phosphorylase $a / a+b$ decreased in adult hepatocytes incubated in $5.7 \mathrm{mM}$ glucose or greater $(p<0.05)$. Fetal phosphorylase a/a+b was increased at $8.3 \mathrm{mM}$ or greater glucose $(p<$ $0.05)$. In contrast, both adult and fetal phosphorylase were activated by glycogen. A glucose-induced increase in active phosphorylase may induce the decrease in net glycogenic rate at high glucose in fetal hepatocytes. A substratecontrolled balance between synthesis and degradation permits appropriate but not excessive glycogen storage in the fetal hepatocyte. (Pediatr Res 32: 714-718, 1992)
\end{abstract}

Hepatic glycogenesis commences in the rat fetus at $17 \mathrm{~d}$ of gestation. In the interval between delivery (d 21.5) and the onset of gluconeogenesis, the large quantities of accrued hepatic glycogen are rapidly used. Because rat fetal liver does not have an active gluconeogenic path (phosphoenol pyruvate carboxykinase activity appears only after birth), all glycogenesis must proceed through the direct glycogenic path. It has been suggested that induction of glycogen synthase activity by rising insulin levels at d 17 of gestation is the driving force for glycogenesis in this species. Further, elevated glycogen synthase activity is associated with stable low activity of the controlling glycogenolytic hormone, glycogen phosphorylase (1). Fetal hepatic glycogen content is controlled to some extent by maternal glucose supply to

Received January 27, 1992; accepted July 29, 1992.

Correspondence and reprint requests: Lynne L. Levitsky, M.D., Pediatric Endocrine Unit, 709 Wang ACC, Massachusetts General Hospital, 15 Parkman St., Boston, MA 02114

Supported by USPHS Grant HD22891. the fetus (2-5). The intrauterine growth-retarded fetus stores a diminished amount of hepatic glycogen, whereas the large fetus of the experimental diabetic dam has larger glycogen stores (3, 4). Whether this control is mediated by fetal insulinemia is not clear. To understand better the regulation of glycogen synthesis in the rat fetus, we have examined the glycogenic response to medium glucose of the fetal and adult rat hepatocyte cultured with cortisol and insulin. Further, we have correlated this response with studies of glycogen synthase and phosphorylase activity under the same conditions. These studies allow us to assess the capacity for autoregulation of glycogenesis in the fetal hepatocyte and to reassess the relationship between glycogenesis and glycogenolysis during the active net glycogenesis of late fetal life.

\section{MATERIALS AND METHODS}

Isolation of hepatocytes. All studies were carried out using hepatocytes isolated from Sprague-Dawley rats (Charles River Breeding Laboratories, Inc., Wilmington, MA). All laboratory animal studies were conducted humanely according to National Institutes of Health guidelines for the use and care of laboratory animals and were approved by the Institutional Committee on Research. Adult male rat hepatocytes were prepared using the method of Seglen (6). Rats were anesthetized with ketamine/ xylazine, and livers were perfused with collagenase under sterile nonrecirculating conditions. The cell suspension was filtered through $250-$ and $62-\mathrm{nm}$ nylon mesh and centrifuged at $400 \mathrm{rpm}$ for $3 \mathrm{~min}$ at $4^{\circ} \mathrm{C}$. The cell pellet was resuspended in cold balanced salt solution and washed twice. Viability was $85-95 \%$ by trypan blue exclusion. Fetal rat hepatocytes were prepared by the method of Freemark and Handwerger (7). Three to four litters were obtained at $20 \mathrm{~d}$ of gestation, the livers removed under sterile conditions, and hepatocytes isolated from minced livers incubated with shaking at $37^{\circ} \mathrm{C}$ in collagenase. Collagenasetreated liver tissue was filtered through $150-\mathrm{nm}$ nylon mesh and incubated with desoxyribonuclease- $1(0.002 \%)$ at room temperature for $15 \mathrm{~min}$. The cell suspension was filtered through 62 $\mathrm{nm}$ nylon mesh and centrifuged at $400 \mathrm{rpm}$ for $3 \mathrm{~min}$ at $4^{\circ} \mathrm{C}$. The cell pellet was resuspended and washed three times with balanced salt solution. Viability was above $95 \%$ by trypan blue exclusion.

Hepatocyte culture. Cells were cultured for $48 \mathrm{~h}$ in Dulbecco's modified Eagle's medium (D 5030, Sigma Chemical Co., St. Louis, MO) supplemented with $0.2 \mathrm{mM}$ glutamine, aspartate, and serine; $0.1 \mathrm{mM}$ pyruvate; $1.0 \mathrm{mM}$ glucose; $10 \mu \mathrm{M}$ cortisol; $1 \mu \mathrm{M}$ porcine insulin; $50 \mu \mathrm{g} / \mathrm{mL}$ gentamycin; $5 \mu \mathrm{g} / \mathrm{mL}$ amphotericin B; and $10 \%$ FCS. Cells were plated in collagen-coated 60 $\mathrm{mm}$ wells at $1.5 \times 10^{6} / 2-\mathrm{mL}$ well for adult hepatocytes and 3.5 $\times 10^{6} / 2 \mathrm{~mL}$ well for fetal hepatocytes. Medium was changed at 
2 and $24 \mathrm{~h}$, removing residual hematopoietic elements from fetal hepatocytes and damaged cells from both groups.

Glycogenesis studies. After 48 h of culture, cells were incubated for $4 \mathrm{~h}$ in $2 \mathrm{~mL}$ FCS-free medium per well with 1, 2, 5.7, 8.3, $11.1,20$, or $30 \mathrm{mM}$ glucose and $0.5 \mu \mathrm{Ci} \mathrm{U}-{ }^{14} \mathrm{C}$-glucose. The incubation was terminated by aspirating the medium and harvesting the cells into $1 \mathrm{~mL} 0.03 \mathrm{~N} \mathrm{HCl}$. Cells were stored at $-20^{\circ} \mathrm{C}$ until assayed for $\mathrm{U}-{ }^{14} \mathrm{C}$-glucose incorporation into glycogen and net glycogenesis using the method of Chan and Exton (8). Glycogenesis was quantitated as glucose incorporation in $\mu \mathrm{M} / \mathrm{g}$ protein. Protein was assayed using the Bradford dye method with BSA as the standard (Bio-Rad Laboratories, Richmond, CA). A comparison with total DNA was made using the method of Burton and 2-deoxy- $d$-ribose $\left(10^{-7} \mathrm{M}\right)$ as standard (9).

Enzyme assays. Hepatocytes cultured for $48 \mathrm{~h}$ were incubated for $4 \mathrm{~h}$ in FCS-free medium containing 1, 5.7, 8.3, or $30 \mathrm{mM}$ glucose. In some studies, glucagon was added $10 \mathrm{~min}$ before termination of incubation. Incubation was terminated by two rapid washes in cold buffered salt solution, and the plates were floated on liquid nitrogen. Cells were stored at $-70^{\circ} \mathrm{C}$ until enzyme assay. Cells were harvested in $0.3 \mathrm{~mL}$ of iced medium containing $50 \mathrm{mM}$ Tris buffer, $100 \mathrm{mM}$ sodium fluoride, $10 \mathrm{mM}$ EDTA, $0.5 \%$ rabbit liver glycogen purified using a mixed-bed ion exchange resin before use, and $5 \mathrm{mM}$ DTT, $\mathrm{pH}$ 6.8. The cell suspension was homogenized for $1 \mathrm{~min}$ on ice using a Tekmar Tissumizer (Tekmar Co., Cincinnati, $\mathrm{OH}$ ). This homogenate was used within $1 \mathrm{~h}$ after preparation for both synthase and phosphorylase assays performed using the method of Golden et al. (10). Synthase a was assayed in the presence of $15 \mathrm{mM} \mathrm{Na}_{2} \mathrm{SO}_{4}$, and total synthase in the presence of $3 \mathrm{mM}$ glucose-6-phosphate. After $40 \mathrm{~min}$ at $37^{\circ} \mathrm{C}$, the incubation was terminated by delivering replicate $50-\mu \mathrm{L}$ aliquots to a chloride resin column (AG 1X8, 100-200 mesh) and washing with distilled water. One unit of glycogen synthase activity is the amount of the enzyme that incorporates $1 \mu \mathrm{mol}$ of UDPglucose per min into glycogen. Phosphorylase was measured in the direction of glycogen synthesis by measuring the incorporation of ${ }^{14} \mathrm{C}$-glucose- 1 -phosphate into glycogen over $20 \mathrm{~min}$. One unit of glycogen phosphorylase activity was expressed as the amount of enzyme that incorporated $1 \mu \mathrm{M}$ of ${ }^{14} \mathrm{C}$-glucose from $\mathrm{U}^{1{ }^{14}} \mathrm{C}$-glucose-1-phosphate in the presence of $0.75 \mathrm{mM}$ caffeine (a form) or in the presence of 7.5 mM AMP $(a+b$ form) per min into glycogen.

Statistical analysis. All data are expressed as mean \pm SEM. Logarithmic transformation was used to normalize values before analysis. A paired $t$ test with Bonferroni correction was used for multiple comparisons among groups. Significance has been expressed after correction. Analysis of variance with post hoc Tukey test was used for comparisons between adult male and fetal hepatocytes.

\section{RESULTS}

Incorporation of medium glucose as ${ }^{14} \mathrm{C}$-glucose into glycogen was significantly greater in fetal hepatocytes than in adult hepatocytes at all glucose concentrations from 1 to $30 \mathrm{mM}(p<$ 0.001 ) (Fig. 1 $A$ ). The patterns of the concentration-response curve for fetal and adult hepatocytes were different. In fetal hepatocytes, incorporation was observed at $1 \mathrm{mM}$ medium glucose, and the rise in the rate of incorporation was greater before $8.3 \mathrm{mM}$ glucose (7.7- \pm 1.1 -fold increase compared with a 3.8\pm 0.6 -fold increase in adult cells). However, in adult hepatocytes, glucose incorporation was observed only at $5.7 \mathrm{mM}$ glucose and accelerated from 8.3 to $30 \mathrm{mM}$. There was a $19.4- \pm 2.7$-fold increase in glycogen accumulated between 8.3 and $30 \mathrm{mM}$ glucose in the adult and only a 1.6- \pm 0.1 -fold increase over this glucose range in the fetus. Total glycogen accumulation measured as glucosyl units was similar in fetal cultures (Fig. $1 B$ ). In cultures of adult hepatocytes, total glycogen accumulation exceeded glucose incorporation and the gap between glycogen
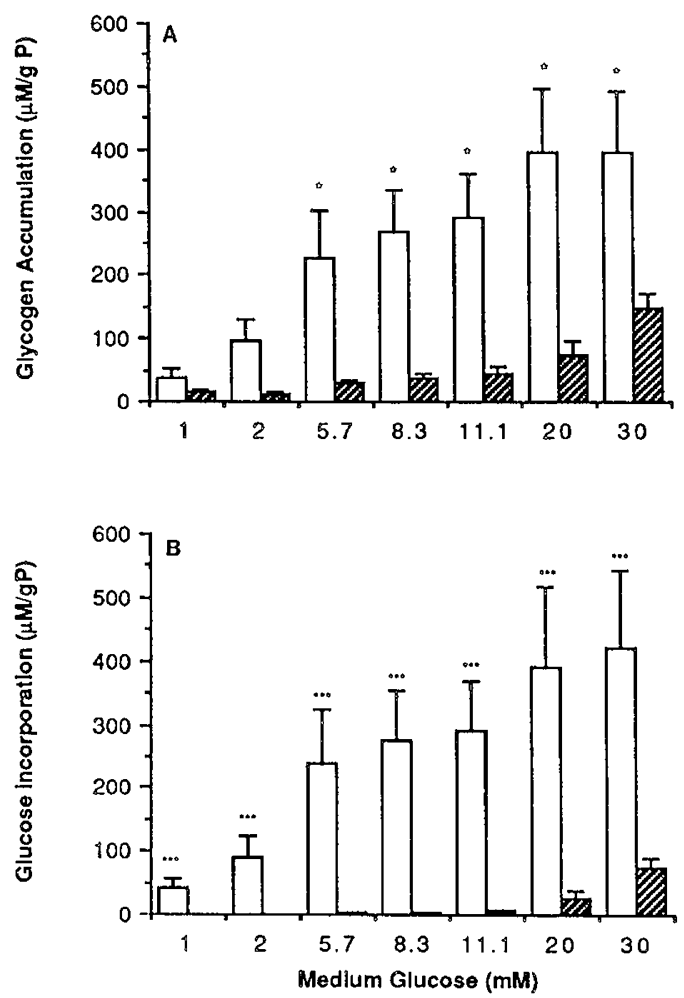

Fig. 1. Glycogen accumulation in fetal (open bars) and adult hepatocytes (striped bars) cultured for $4 \mathrm{~h}$ at $1,2,5.7,8.3,11.1,20$, or 30 $\mathrm{mM}$ glucose and $0.5 \mu \mathrm{Ci} \mathrm{U-}{ }^{14} \mathrm{C}$-glucose. Accumulation as ${ }^{14} \mathrm{C}$-glucose is depicted in $A$ and net glycogen accumulation is depicted in $B$.

accumulation and glucose incorporation diminished as medium glucose rose, but glucose incorporation was never more than half of total glycogen incorporation, reflecting the use of other precursors for glycogenesis. All data are expressed per mg protein. Fetal hepatocytes are smaller than adult hepatocytes. Therefore, fetal-to-adult comparisons do not compare glycogenesis per cell. In the fetal cultures, there were $12.1 \pm 0.6 \mu \mathrm{g} \mathrm{DNA} / \mathrm{mg}$ protein $(n=5)$, and in the adult, $9.5 \pm 0.9 \mu \mathrm{g} \mathrm{DNA} / \mathrm{mg}$ protein $(n=3)$. Therefore, adult values are approximately $20 \%$ higher compared with fetal if expressed as glycogen per $\mu \mathrm{g}$ DNA.

We examined the activity of glycogen synthase and phosphorylase in the cultured hepatocytes incubated at various medium glucose concentrations to see if the activity of enzymes of glycogen synthesis and degradation contributed to the pattern of glycogen accumulation that we observed in the cultured fetal and adult hepatocytes. Glycogen synthase a activity was stimulated significantly by $30 \mathrm{mM}$ medium glucose in both adult and fetal hepatocytes (Fig. 2). Total synthase activity was significantly higher in fetal hepatocytes compared with adult hepatocytes $(p$ $<0.001$ ), but the active a form was similar in fetal and adult hepatocytes. Total synthase activity did not change with increasing medium glucose in either fetal or adult cells. Glycogen synthase $a / a+b$ ratio in fetal hepatocytes was significantly greater at 8.3 and $30 \mathrm{mM}$ than in cells studied at lower medium glucose concentrations. Glycogen synthase $\mathrm{a} / \mathrm{a}+\mathrm{b}$ ratio in adult cells was significantly increased at $5.7 \mathrm{mM}$ medium glucose or greater. As expected, phosphorylase a activity was inhibited by elevated medium glucose (8.3 and $30 \mathrm{mM}$ ) in adult hepatocytes (Fig. 3). Total phosphorylase did not change with medium glucose, and glycogen phosphorylase $a / a+b$ decreased from $5.7 \mathrm{mM}$ medium glucose. In contrast, fetal active glycogen phosphorylase increased. Total glycogen phosphorylase levels were not different in fetal and adult cells. However, in response to high medium glucose $(5.7$ and $8.3 \mathrm{mM}$ ), fetal hepatocyte phosphorylase a activity was stimulated compared with low medium glucose. At 

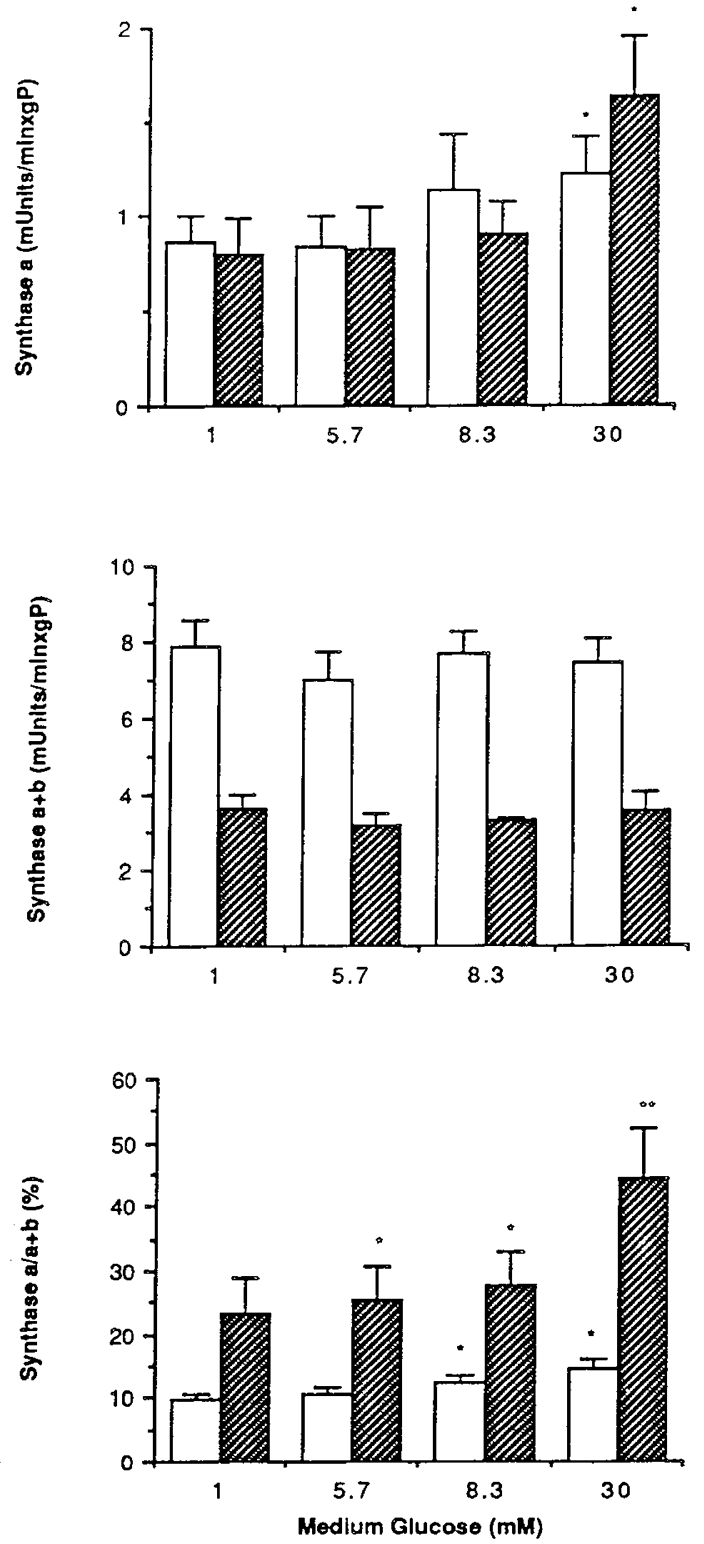

Fig. 2. Glycogen synthase activity in fetal (open bars) and adult hepatocytes (striped bars) incubated in $1,5.7,8.3$, or $30 \mathrm{mM}$ glucose.

$30 \mathrm{mM}$, fetal hepatocyte phosphorylase a activity was neither significantly stimulated nor inhibited. The ratio of phosphorylase $\mathrm{a} /(\mathrm{a}+\mathrm{b})$ was significantly increased in the fetal hepatocyte at 8.3 and $30: \mathrm{mM}$ medium glucose compared with lower medium glucose concentrations.

To examine whether fetal phosphorylase behaved differently to other stimuli, cells were cultured for $45 \mathrm{~h}$ as described and incubated for $4 \mathrm{~h}$ with 1 or $8 \mathrm{mM}$ glucose. Glucagon $\left(10^{-7} \mathrm{M}\right)$ was then added, and phosphorylase activity was measured after $10 \mathrm{~min}$ of incubation. Phosphorylase was fully activated in fetal and adult cells incubated at both 1 and $8 \mathrm{mM}$ glucose (Fig. 4).

\section{DISCUSSION}

The adult hepatocyte in the postprandial state is supplied by the portal vein with concentrations of glucose greater than $8 \mathrm{mM}$ and endowed with the capacity for indirect glycogenesis through the gluconeogenic path. In the adult hepatocyte, the high-Km glucose transporter, GLUT 2, and the high-Km hexokinase, glucokinase, are sufficient to ensure glucose supply to the hepatocyte for glycogenesis by the direct route $(11,12)$. In contrast, the fetal rat liver stores glycogen at a rapid rate from d 17 of gestation to term despite the absence of the gluconeogenic path,
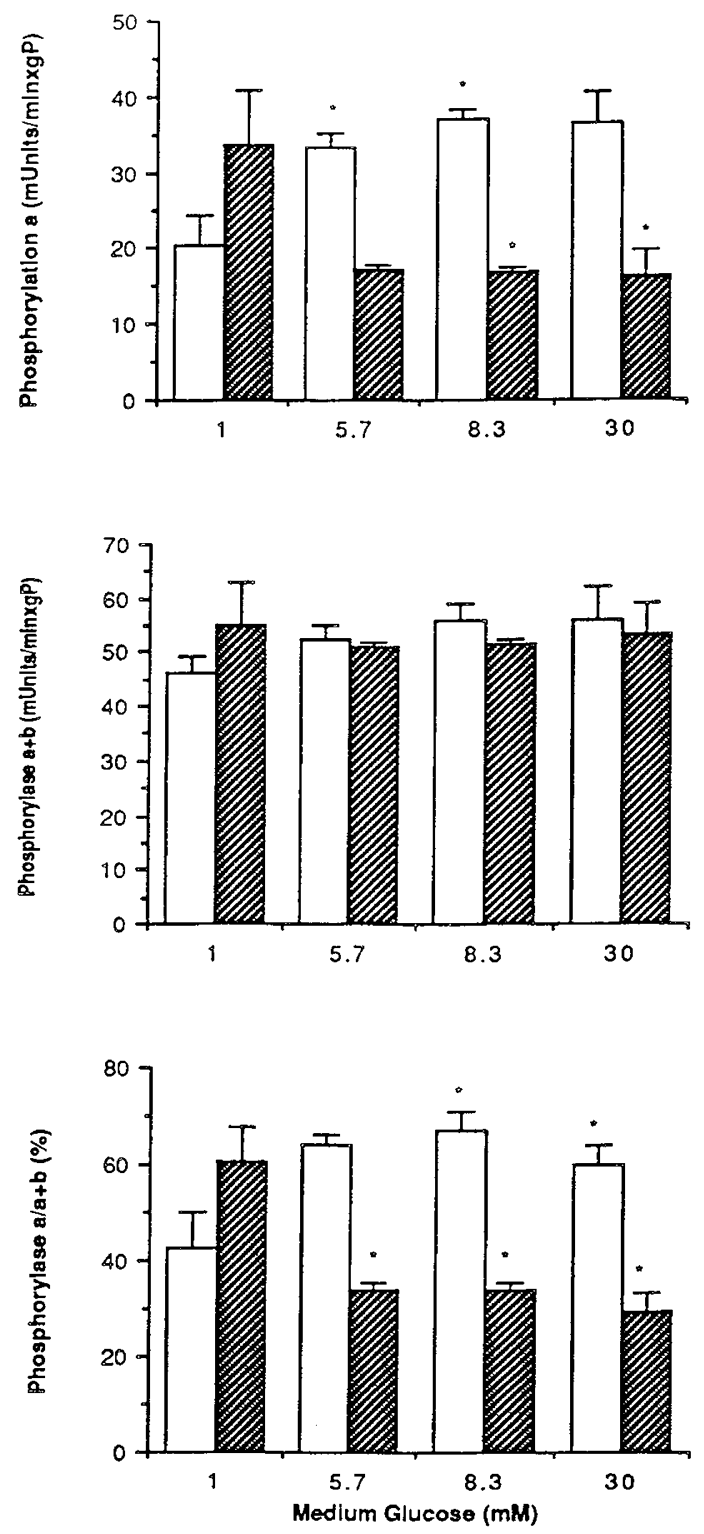

Fig. 3. Glycogen phosphorylase activity in fetal (open bars) and adult hepatocytes (striped hars) incubated in $1,5.7,8.3$, or $30 \mathrm{mM}$ glucose.

and a limited glucose supply (13). The fetal liver is supplied with substrate largely by umbilical vein blood and is therefore exposed to a glucose concentration that is approximately $70 \%$ of maternal peripheral blood. We have demonstrated, as have other workers, an increased capacity for glycogenesis at low medium glucose in the fetal rat hepatocyte (14). This capacity may be related to enhanced transport of glucose at low ambient glucose levels as well as to the presence of low-Km hexokinases in fetal hepatocytes, permitting glucose phosphorylation at relatively low levels of glucose $(15,16)$. Nonetheless, the drive to net glycogen accumulation rests in the relationship between glycogen synthase and glycogen phosphorylase.

Glycogen synthase and phosphorylase are regulated by phosphorylation-dephosphorylation reactions at multiple sites (1719). We demonstrate that phosphorylase activation by glucagon is similar in fetal and adult hepatocytes. Dephosphorylation leading to activation of glycogen synthase a is intimately related to inactivation of phosphorylase after dephosphorylation by the specific phosphatase, protein phosphatase-1. Cohen (20) has proposed that allosteric inhibition of protein phosphatase- 1 by phosphorylase a explains the known coordinate activation of glycogen synthase after inactivation of phosphorylase. Allosteric regulation by glycogenic substrates (glucose, glucose-6-phos- 

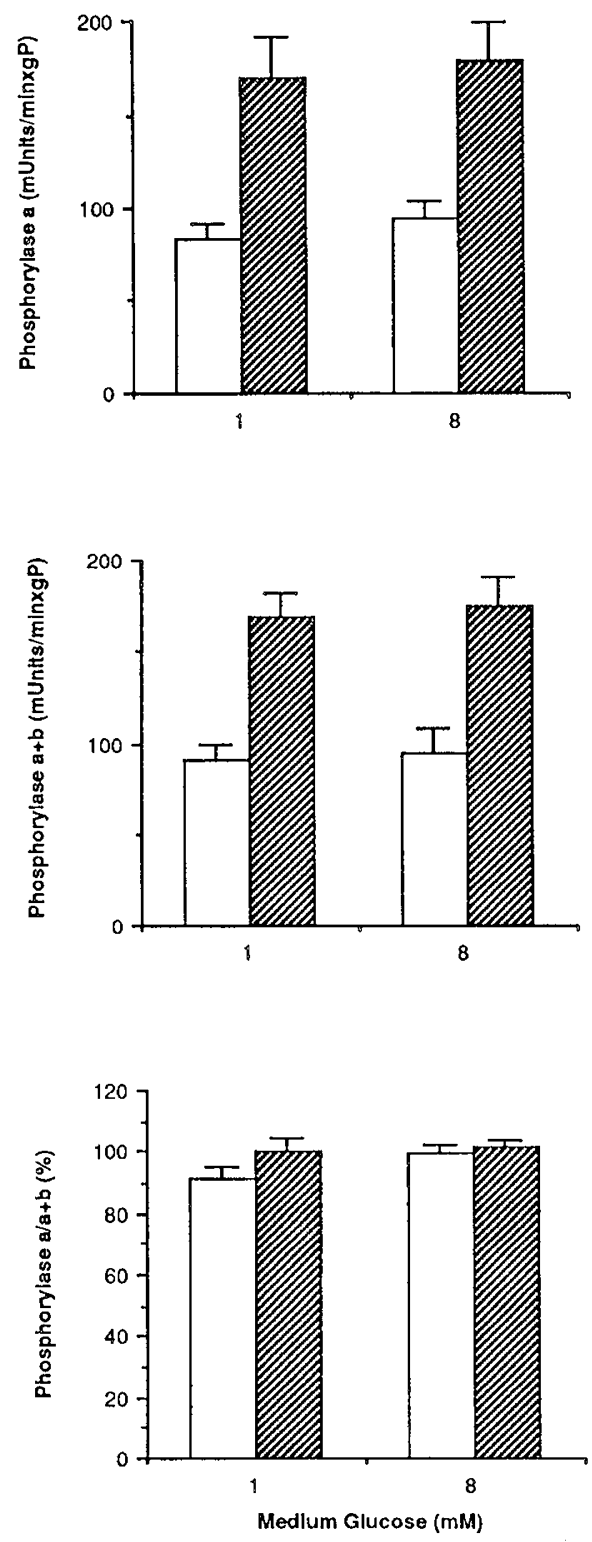

Fig. 4. Glycogen phosphorylase activity in fetal (open bars) and adult hepatocytes (striped bars) incubated in 1 and $8 \mathrm{mM}$ glucose and then exposed to glucagon $\left(10^{-7} \mathrm{M}\right)$ for $10 \mathrm{~min}$.

phate, and glucose-1-phosphate) also governs the state of activation of glycogen synthase and glycogen phosphorylase. Glucose binds to an active site on the muscle and liver glycogen phosphorylase molecule, enhancing the phosphatase activity $(17,21$, 22). Therefore, glycogen accumulation in the adult hepatocyte exposed to medium glucose levels equal to or substantially higher than that normally found in vivo may be readily explained by complementary increased active glycogen synthase and decreased active phosphorylase. Indeed, hyperglycemia leads to almost complete inactivation of glycogen phosphorylase followed by activation of glycogen synthase in vitro (23-25). However, phosphorylase inactivation is not always required for in vitro glycogen synthase activation. In isolated adult rat hepatocytes, fructose activates both glycogen synthase and glycogen phosphorylase (26). Further, activation of glycogen synthase by glucose is impaired if glucose 6-phosphate levels are lowered, but phosphorylase is inactivated normally (27).

The complete inactivation of phosphorylase by glucose in vitro has also been counter to in vivo studies. For instance, continuing activity of glycogen synthase and glycogen phosphorylase in the postprandial state has been reported in a number of in vivo studies in adult rats. Nuclear magnetic resonance imaging of adult rat liver in viko provides strong evidence for continued cycles of degradation and synthesis in the fasting and fed state (28). Failure of rapid accumulation of glycogen in the fed state may be related to accelerated glycogen turnover rather than failure of synthesis $(28,29)$. Whether there is glycogen degradation in vivo in the fetal liver is unclear. Maternal glycemia remarkably enhanced fetal liver glycogen content and incorporation of labeled glucose in vivo, whereas phosphorylase a activity fell with modest fetal hyperglycemia $(5.5 \mathrm{mM})$ and synthase a activity rose over a wide range of fetal glucose to $32 \mathrm{mM}(5)$. Glycogen degradation could not be identified in vivo in one study using labeled glucose incorporation and release as a marker (30); however, another study suggested that glycogen synthesis and degradation occurred simultaneously (31).

Hormone-independent activation of glycogen synthase by sugars in cultured adult rat hepatocytes has been noted by several workers. Ciudad et al. (32) reported that synthase is activated by an array of sugars including glucose, mannose, fructose, galactose, and tagatose. It is unclear whether these sugars all work through the same mechanism. Glycogen synthase phosphatase activity is stimulated in glycogen particles by high levels of glucose ( $20 \mathrm{mM}$ or more), leading to activation of synthase (33, 34 ), but other sugars apparently do not stimulate the phosphatase directly (33).

Differences have been identified between fetal and adult liver in regard to the enzymes of glycogenesis. There may be a fetalspecific glycogen synthase isozyme in the late fetal and newborn rat and mouse (35). In addition, protein phosphatase- 1 could be differently regulated during fetal life (4). We suggest several hypotheses to explain the increase of active phosphorylase in fetal hepatocytes exposed to increased medium glucose. The fetal hepatocyte differs from the adult hepatocyte in glycogen content (many-fold greater than the adult at the end of incubation). Fleig et al. (34) have demonstrated that glycogen storage decreases with increasing glycogen content in the cultured adult hepatocyte. In skeletal muscle, high levels of glycogen inhibit glycogen synthase activation and inhibit phosphatase, enhancing glycogen breakdown $(36,37)$. Hepatocytes isolated from fed adult animals accumulate glycogen much less readily than those from fasted animals (38). Hepatocytes incubated in high glucose medium before study also do not accumulate glycogen as readily as those that are glycogen-depleted (39). Enhancing the glycogen content of a liver cell filtrate has been demonstrated to inhibit phosphorylase phosphatase activity (40) as well as synthase phosphatase (41). There is glycogenolysis in freshly isolated hepatocytes from fed rats even in high glucose medium (23). The effects of glycogen on phosphorylase activation are probably not direct effects of phosphatase. Glycogen activates phosphorylase $\mathrm{a}$ and $\mathrm{b}$ by binding to the glycogen storage or activation sites of the muscle isozyme, and probably the liver isozyme as well (21). One might also hypothesize that fetal phosphorylase differs structurally from adult phosphorylase and does not have a sensitive glucose-active site. Earlier studies using electrophoretic separation of phosphorylase isozymes suggested that fetal rat liver contained largely the phosphorylase isozyme found postnatally only in brain and in some neoplastic tissues (42-44). The nature of glucose control of the rat brain phosphorylase has not yet been defined. Certain naturally occurring phosphorylases (potato, yeast), do not respond to glucose control (22). It is entirely possible that brain phosphorylase is similar, although the active sites of the glucose binding regions of human and rabbit brain phosphorylase have been mapped and do not differ from muscle and liver phosphorylase (45). Further, in both human and rabbit fetal liver tissues, it has not been possible to confirm a predominant "fetal phosphorylase" using molecular cloning techniques $(45,46)$. A third possibility is that the failure of suppression of fetal phosphorylase at high medium glucose levels is related to the rapid rate of phosphorylation of transported glucose in the fetal cells, because glucose 1-phosphate allosterically enhances phosphorylase activ- 
ity (21). The rapid phosphorylation of intracellular glucose would therefore assure a different intracellular milieu for the fetal compared with the adult hepatocyte. Whatever the mechanism of failure of suppression of phosphorylase in the fetal hepatocyte, the presence of active phosphorylase in fetal hepatocytes at high medium glucose concentration is likely one mechanism for the nonlinear relationship between net glycogen accrual and medium glucose.

Glycogen accumulation in isolated fetal hepatocytes is enhanced by medium cortisol and insulin $(47,48)$. Cortisol apparently has a basal permissive effect on glycogenesis in vivo, because fetal cortisol deficiency diminishes hepatic glycogen stores experimentally (49). Fetal insulin deficiency may not be sufficient to diminish glycogen stores (4). The hyperinsulinism of the fetus of the diabetic dam enhances fetal hepatic glycogen stores (3). Experimental fetal hyperinsulinemia without elevation in glycemia also enhances glycogen stores (2). However, it is unlikely that the normal fetus is exposed to acute changes in insulin in vivo or that such acute changes influence the moment-to-moment regulation of hepatic glycogen accumulation. Insulin response to acute glucose elevation is sluggish in the fetus, unless there has been continued exposure to hyperglycemia (50). The glycogenolytic response to glucagon is much less in fetal life than in postnatal life (51). Therefore, hormonally independent intrinsic regulatory mechanisms may be important in maintenance of the homeostasis of energy storage during fetal life. The balance between glycogen synthesis and degradation is critical in permitting the development of appropriate but not excessive glycogen stores in the fetal hepatocyte.

Acknowledgment. The authors thank Dr. Christopher B. Newgard, University of Texas, Southwestern Medical Center, for his helpful discussion.

\section{REFERENCES}

1. Margolis RN 1983 Regulation of hepatic glycogen metabolism in pre- and postnatal rats. Endocrinology 113:893-902

2. Bourbon J, Gilbert M 1981 Role of fetal insulin in glycogen metabolism in the liver of the rat fetus. Biol Neonate 40:38-45

3. Margolis RN, Seminara D 1988 Glycogen metabolism in late gestation in fetuses of maternal diabetic rats. Biol Neonate 54:133-143

4. Gruppuso PA, Brautigan DL 1989 Induction of hepatic glycogenesis in the fetal rat. Am J Physiol 256:E49-E54

5. Gilbert M, Bourbon J 1980 Effects of acute variation of fetal glycemia on glycogen storage and on glycogen synthase and phosphorylase activities in the liver of the rat fetus. Diabetes 29:266-271

6. Seglen PO 1976 Preparation of isolated rat liver cells. Methods Cell Biol 13:2983

7. Freemark M, Handwerger S 1984 Ovine placental lactogen stimulates glycogen synthesis in fetal rat hepatocytes. Am J Physiol 246:E21-E24

8. Chan TM, Exton JH 1976 A rapid method for the determination of glycogen content and radioactivity in small quantities of tissue or isolated hepatocytes. Anal Biochem 71:96-105

9. Burton K 1956 A study of the conditions and mechanism of the diphenylamine reaction for the colorimetric estimation of desoxy ribonucleic acid. Biochemistry 162:315-323

10. Golden S, Wals PA, Katz J 1977 An improved procedure for the assay of glycogen synthase and phosphorylase in rat liver homogenates. Anal Biochem 77:436-445

11. Bell GI, Kayano T, Buse JB, Burant CF, Takeda J, Lind D, Fukumoto H, Seino S 1990 Molecular biology of mammalian glucose transporters. Diabetes Care 13:198-208

12. Pilkis SJ, Regen DM, Claus TH, Cherrington AD 1985 Role of hepatic glycolysis and gluconeogenesis in glycogen synthesis. Bioessays 2:273-276

13. Watts C, Gain KR 1976 Glycogen metabolism in the liver of the developing rat. Biochem J 160:263-270

14. Sinha MK, Miller JD, Sperling MA, Suchy FJ, Ganguli S 1984 Possible dissociation between insulin binding and insulin action in isolated fetal rat hepatocytes. Diabetes 33:864-871

15. Ballard FJ, Oliver IT 1964 The effect of concentration on glucose phosphorylation and incorporation into glycogen in the livers of foetal and adult rats and sheep. Biochem J 92:131-136

16. Ballard FJ, Oliver IT 1964 Ketohexokinase, isoenzymes of glucokinase and glycogen synthesis from hexoses in neonatal rat liver. Biochem J 96:261268

17. Madsen NB 1986 Glycogen phosphorylase. In: Boyer PD, Krebs EG (eds) The Enzymes XVIIA. Academic Press, San Diego, pp 365-395
18. Roach PJ 1986 Liver glycogen synthase. In: Boyer PD, Krebs EG (eds) The Enzymes XVIIA. Academic Press, San Diego, pp 499-539

19. Roach PJ 1990 Control of glycogen synthase by hierarchal protein phosphorylation. FASEB J 4:2961-2968

20. Cohen P 1989 The structure and regulation of protein phosphatases. Annu Rev Biochem 58:453-508

21. Newgard CB, Hwang PK, Fletterick RJ 1989 The family of glycogen phosphorylases: structure and function. CRC Crit Rev Biochem Mol Biol 24:69-99

22. Fletterick RJ, Burke JA, Hwang PK, Nakano K, Newgard CB 1986 Structural relationships in glycogen phosphorylases. Ann NY Acad Sci 478:220-231

23. Hue L, Bontemps F, Hers HG 1975 The effect of glucose and of potassium ions on the interconversion of the two forms of glycogen phosphorylase and of glycogen synthetase in isolated rat liver. Biochem J 152:105-114

24. Stalmans W, DeWulf H, Hue L, Hers HG 1974 The sequential inactivation of glycogen phosphorylase and activation of glycogen synthetase in liver after the administration of glucose to mice and rats. Eur J Biochem 41:127-134

25. Hers HG 1976 The control of glycogen metabolism in the liver. Annu Rev Biochem 45:167-189

26. Ciudad CJ, Massague J, Guinovart JJ 1979 The inactivation of glycogen phosphorylase is not a prerequisite for the activation of liver glycogen synthase. FEBS Lett 99:321-324

27. Ciudad CJ, Carabaza A, Guinovart JJ 1986 Glucose-6-phosphate plays a central role in the activation of glycogen synthase by glucose in hepatocytes. Biochem Biophys Res Commun 141:1195-1200

28. David M, Petit WA, Laughlin MR, Shulman RG, King JE, Barrett EJ 1990 Simultaneous synthesis and degradation of rat liver glycogen. J Clin Invest 86:612-617

29. Niewoehner CB, Nuttall FQ 1989 Disposition of a glucose load in fed rats and rats adapted to a high-carbohydrate diet. Am J Physiol 256:E811-E817

30. Devos P, Hers HG 1974 Glycogen metabolism in the liver of the foetal rat. Biochem J 140:331-340

31. Gilbert M, Bourbon J 1978 Turnover of liver glycogen in the rat fetus. Biochem J $176: 785-789$

32. Ciudad CJ, Carabaza A, Bosch F, Gomez I, Fox AM 1988 Glycogen synthase activation by sugars in isolated hepatocytes. Arch Biochem Biophys 264:3039

33. Gilboe DG, Nuttall FQ 1984 Direct glucose stimulation of glycogen synthase phosphatase activity in a liver glycogen particle preparation. Arch Biochem Biophys 228:587-591

34. Fleig WE, Enderle D, Steudter S, Nöther-Fleig G, Ditschuneit H 1987 Regulation of basal and insulin-stimulated glycogen synthesis in cultured hepatocytes: inverse relationship to glycogen content. J Biol Chem 262:11551160

35. Gold AH 1987 Structural studies on neonatal rat liver glycogen synthase: a comparison between adult and newborn synthase phosphopeptides. Arch Biochem Biophys 256:202-211

36. Villar-Palasi C 1969 Oligo and polysaccharide inhibition of muscle transferase D phosphatase. Ann NY Acad Sci 166:719-729

37. Mellgren RL, Coulson M 1983 Coordinated feedback regulation of muscle glycogen metabolism: inhibition of purified phosphorylase phosphatase by glycogen. Biochem Biophys Res Commun 114:148-154

38. Katz J, Golden S, Walls PA 1979 Glycogen synthesis by rat hepatocytes. Biochem J 80:389-402

39. Fleig WE, Nöther-Fleig G, Steudter S, Enderle D, Ditschuneit H 1985 Regulation of insulin binding and glycogenesis by insulin and dexamethasone in cultured rat hepatocytes. Biochim Biophys Acta 847:352-361

40. Mvumbi L, Bollen M, Stalmans W 1985 Calcium ions and glycogen act synergistically as inhibitors of hepatic glycogen synthase phosphatase. Biochem J 232:697-704

41. Staimans W, DeWulf $H$, Hers HG 1971 The control of liver glycogen synthetase phosphatase by phosphorylase. Eur J Biochem 18:582-587

42. Sato K, Morris HP, Weinhouse S 1972 Phosphorylase: a new isozyme in rat hepatic tumors and fetal liver. Science 178:879-881

43. Richter F, Böhme H-J, Hofmann E 1988 Changes of glycogen phosphorylase isozyme pattern, in rat tissues during pre- and postnatal development. Biomed Biochim Acta 47:743-752

44. Richter F, Böhme H-J, Hofmann E 1983 Developmental changes of glycogen phosphorylase b isozymes in rat tissues. Biomed Biochim Acta 42:12291235

45. Newgard CB, Norkiewicz B, Hughes SD, Frenkel RA, Coats WS, Martiniuk F, Johnston JM 1991 Developmental expression of glycogenolytic enzymes in rabbit tissues: possible relationship to fetal lung maturation. Biochim Biophys Acta 1090:333-342

46. Newgard CB, Littman DR, vanGenderen C, Smith M, Fletterick RJ 1988 Human brain glycogen phosphorylase. J Biol Chem 263:3850-3857

47. Plas C, Chapeville F, Jacquot R 1973 Development of glycogen storage ability under cortisol control in primary cultures of fetal rat hepatocytes. Dev Biol 32:82-91

48. Plas C, Forest N, Pringault E, Menuelle P 1982 Contribution of glucose and gluconeogenic substrate to insulin-stimulated glycogen synthesis in cultured fetal hepatocytes. J Cell Physiol 113:475-480

49. Jacquot R, Kretchmer N 1974 Effect of fetal decapitation on enzymes of glycogen metabolism. J Biol Chem 239:1301-1304

50. Phillips AF, Dubin JW, Raye JR 1979 Response of the fetal and newborn lamb to glucose and tolbutamide infusions. Pediatr Res 13:1375-1378

51. Vinicor F, Higdon G, Clark JF, Clark CM 1976 Development of glucagon sensitivity in neonatal rat liver. J Clin Invest 58:571-578 